\title{
"Sandstorm" image: bone scintigraphy in pulmonary alveolar microlithiasis
}

\author{
Gordana Horvatić Herceg • Irena Bračić • \\ Marta Koršić • Davorin Herceg • Ratimir Petrović • \\ Sanja Kusačić Kuna $\cdot$ Damir Dodig
}

Received: 12 March 2009/Accepted: 25 March 2009/Published online: 27 May 2009

(C) Springer-Verlag 2009

Pulmonary alveolar microlithiasis (PAM) is a rare idiopathic disorder, usually with familial association, leading to alveolar deposition of calcium phosphate microliths $[1,2]$.

A 48-year-old female patient was referred to our clinic for bone scintigraphy because of severe osteoporosis (L1-L4 T score was -3.5 ; serum calcium values and 24 -h calciuria in normal range).

Bone scintigraphy showed bilateral, intense pulmonary ${ }^{99 \mathrm{~m}} \mathrm{Tc}$-methylenediphosphonate uptake, which led

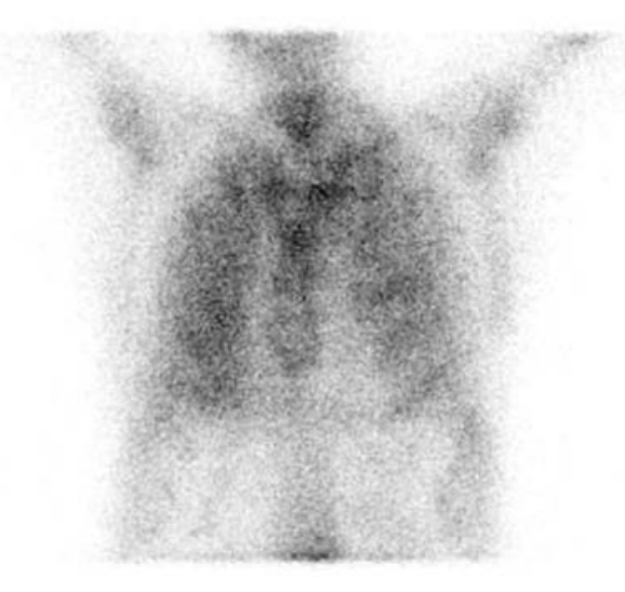

G. Horvatić Herceg $(\bowtie) \cdot$ I. Bračić $\cdot$ R. Petrović •

S. Kusačić Kuna $\cdot$ D. Dodig

Clinical Department of Nuclear Medicine

and Radiation Protection, Clinical Hospital Centre Zagreb,

Zagreb, Croatia

e-mail: gherceg@lycos.com

M. Koršić

Clinical Hospital for Lung Diseases "Jordanovac",

Zagreb, Croatia

D. Herceg

Department of Medical Oncology,

Clinical Hospital Centre Zagreb,

Zagreb, Croatia us to clinical suspicion of PAM. The chest radiograph revealed extensive, bilateral micronodular sand-like appearance, predominantly in the lower lung fields [3].

The diagnosis of PAM was confirmed by transbronchial lung biopsy.

Although the bone scintigraphy finding is sometimes negative in the early stage of PAM [4], this imaging method could be very useful in the detection of PAM.

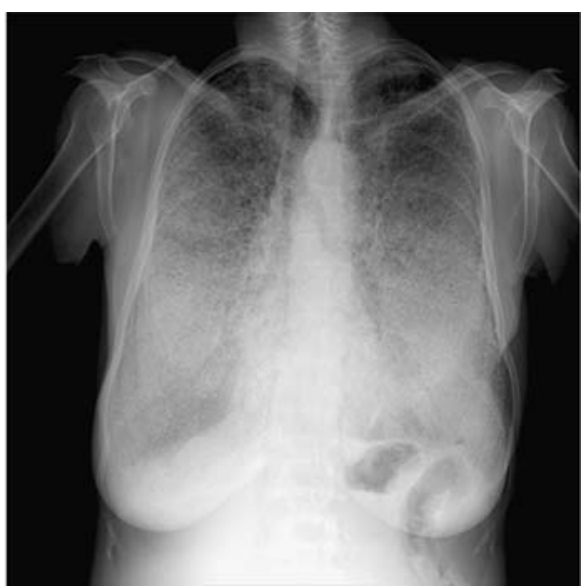

\section{References}

1. Edelman JD, Bavaria J, Kaiser LR, Litzky LA, Palevsky HI, Kotloff RM. Bilateral sequential lung transplantation for pulmonary alveolar microlithiasis. Chest 1997;112:1140-4. doi:10.1378/chest.112.4.1140.

2. Moran CA, Hochholzer L, Hasleton PS, Johnson FB, Koss MN. Pulmonary alveolar microlithiasis. A clinicopathologic and chemical analysis of seven cases. Arch Pathol Lab Med 1997;121:607-11.

3. Shah TC, Talwar A, Shah RD, Margouleff D. Pulmonary alveolar microlithiasis: radiographic and scintigraphic correlation. Clin Nucl Med 2007;32 3:249-51. doi:10.1097/01.rlu.0000255251.87023.a0.

4. Sahin U, Yildiz M, Bircan HA, Akkaya A, Candir O. Absence of pulmonary uptake of Tc-99m methylenediphosphonate in alveolar microlithiasis. Ann Nucl Med 2004;18 8:695-8. doi:10.1007/ BF02985964. 